Acta bot. bras. 1(1):27-41 (1987)

\title{
A FAMÍLIA LAURACEÂE LINDLEY NO RS BRASIL: GENEROS ENDLICHERIA NEES, LAURUS L. E CRYPTOCARYA R.BR. ${ }^{1}$
}

Pedralli, G. $^{2}$

Recebido em 21.02.86. Aceito em 21.07.86.

\begin{abstract}
RESUMO - Foram constatadas para o Rio Grande do Sul, Brasil, através de revisão taxonômica, uma espécie para o gênero Endlicheria Nees e Laurus L., e duas para o gênero Cryptocarya R. Br. São apresentadas descriçōes, ilustraçōes e uma chave analítica para determinação das espécies deste último gênero.

ABSTRACT - A taxonomic revision has indicated that one species of the genus Endlicheria Nees, one of the genus Laurus L. and two of the genus Cryptocarya R. Br. are found in the State of Rio Grande do Sul, Brazil. The species are described, illustrated and an analytical key is provided to distinguish the two species of Cryptocarya.
\end{abstract}

\section{Introdução}

A familia Lauraceae Lindley pơssui 47 gêneros com cerca de 2500 espécies distribuídos pelas regiões tropicais e subtropicais do mundo. No Brasil, ocorrem 19 gêneros e cerca de 390 espécies (BARROSO, 1978).

A grande maioria das espécies tem importância econômica (madeiras, óleos esseciais, frutos comestíveis) e fitossociológica (GEMBALLA, 1955; GOTTLIEB, 1972; KLEIN, 1974; KOSTERMANS, 1937 e RIZZINI, 1979).

O objetivo principal do presente trabalho foi o estudo taxonômico dos representantes da família Lauraceae, principalmente os pertencentes aos gêneros Endlicheria, Laurus e Cryptocarya, no Estado do Rio Grande do Sul, contribuindo deste modo para o conhecimento da flora regional e nacional e, auxiliando no inventário dos nossos recursos florestais, os quais vêm sofrendo grande devastação nas últimas décadas.

\section{Material e Métodos}

Para coleta de material botânico, foram realizadas excursões pelas diversas regiōes fisiográficas do Estado, no período compreendido entre 1975 e 1981.

As identificações foram realizadas por morfologia comparada, utilizando-se a bibliografia especializada, principalmente os trabalhos de BROWN (1810), KOSTERMANS (1937), MEISSNER (1866), MEZ (1889), NEES VON ESENBECK (1833), PAX (1889) e

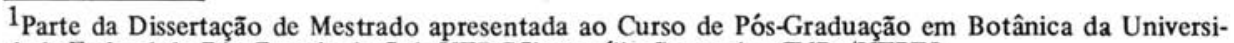
dade Federal do Rio Grande do Sul (UFRGS); auxílio financeiro CNPq/UFPEL.

${ }^{2}$ Biólogo, Setor de Ecossistemas, Fundação Centro Tecnológico de Minas Gerais (CETEC); C.P. 2306; 31170 , Belo Horizonte, MG.
} 
SPRENGEL (1825). Foram, também examinadas para comparações as coleções dos seguintes herbários: GUA, RB, R, ICN, PACA, PEL, HAS, SMDB, MBR, SP, UNB, UEC, coleções particulares do Sr. Karner Hagelund, Arroio dos Ratos, RS e do Sr. Lúcio Arzivenco, Porto Alegre, RS.

Os equipamentos ópticos utilizados foram: microscópio estereoscópico WILD M5A e LEITZ, equipados com iluminação episcópica. (1966).

A diafanização foliar foi realizada segundo o método de FELIPE \& ALENCASTRO

A descrição da morfologia foliar foi baseada no trabalho de HICKFY (1973).

\section{Resultados}

Endlicheria Nees, Linnaea 8: 37, 1833; Kostermans, Rec. Trav. Bot. Néerl. 34: 500-57, 1937, in Med. Bot. Mus. Herb. Rijks Univ. Utrecht 42: 550-1, 1937 et in Reinwardtia 4: 237. 1957; MacBride, Publ. Field Mus. Nat. Hist. 13: 2, 1938 et in Kew Bull. : 102, 1940; Allen, Jour. Arn. Arb. 26: 421, 1945; Vattimo, Arq. Jard. Bot. 15: 127-9, 1957.

Tipo: Endlicheria sericea Nees.

Goeppertia Nees, Syst. Laur., : 365, 1836.

Schauera Nees, in Lindley, Intrd. Nat. Syst. Bot., ed. 2: 202, 1936.

Schaueria Nees ex Meissner, in DC., Prodr. 15(1): 81, 1864 et in Mart., Fl. Bras 5(2): 281, 1866.

Ampelodaphne Meissn., in DC., Prodr. 15(1):81, 1864 et in Mart., Fl. Bras. 5(2): 167, 1866.

Aydendron Gris. (non Nees) p.p., Fl. Brit. W. Ind Isl., : 284, 1860.

Huberodaphne Ducke, Arch. Jard. Bot. 4:191, 1925.

Árvores ou arbustos, folhas alternas, peninérveas; face dorsal muitas vezes densamente pontuada. Panículas axilares ou subterminais. Flores unissexuais, de tubo distinto, raso a subgloboso. Tépalas seis, geralmente iguais, reflexas após a antese. Flores masculinas com nove estames férteis, em três verticilos; estames exteriores biloculares; anteras com os lóculos introrsos ou lateral-introrsos, geralmente sem glândulas. Estames internos eretos com dois lóculos, extrorsos ou lateral-extrorsos; filetes com glândulas basais ou sub-basais. Quarto ciclo de estames geralmente ausente, raro estaminodial, diminuto. Ovário estéril, estipitiforme. Flores femininas, em geral, em panículas mais curtas. Estames semelhantes aos da flor masculina, menores, estéreis. Ovário imerso no tubo, em geral glabro. Estilete curto, crasso; estigma discóide ou peltado. Fruto baga, escura, elipsóide ou ovóide, lisa, cúpula hemisférica ou subpateriforme, margem simples, pedicelo engrossado.

Gênero corrente na América do Sul, América Central, existindo duas espécies nas Antilhas.

Endlicheria paniculata (Spreng.) MacBride, Publ. Field. Mus. Nat. Hist. 13(2): 850, 1938; Sprengel, Syst. 2: 545, 1825; Kostermans, Bol. Inst. Agron. Norte 28: 64, 1953; Vattimo, Arq. Jard. Bot. Rio de Janeiro 15:129-33, 1957 et Rodriguesia 37: 98, 1966. (Figura 1).

Tipo: Citrosma paniculata Spreng.

Citrosma paniculata Spreng, 1.c. et in Mart., El. Bras. 4(1):311, 1857.

Endlicheria hirsuta (Schott) Nees, Linnaea 8: 38, 1833; Mez, Jahrb. Bot. Gart. Mus. Berlin 5: 119, 1889 et in Arb. Bot. Gart. Breslau 1: 113, 1892; Wettstein et Schiffner, Engebn. Exp. Acad. Wiss. Wien 1901: 305, 1908; Glaziou, Bull. Soc. Bot. Fr. 59(3): 590, 1913; Pio Correa, Dic. Pl. úteis Brasil 1: 439, 1926; Hassler, Ann. Cons. Jard. Bot. Genève 21: 77, 1919; Kostermans, Med. Mus. Herb. Utrecht 42: 549-53, 1937; Coe-Teixeira, Bol. Secr. Agr. Est. São Paulo 1: 11-44, 1963.

Goeppertia hirsuta Nees, Syst. Laur., : 366, 1836 (excl. cit. spec. Poeppig app. 90) et Linnaea 21: 513, 1848; Meissner, in DC., Prodr. 15(1): 172, 1864 (excl. var. hirsutior) et in Mart., Fl. Bras. 5(2): 282, 1866, et in Vidensk. Med. Kjobnh., : 145, 1870.

Siparuna paniculata (Spreng.)DC., Prodr. 16(2): 656, 1868; Perkins et Gilg in Engler, Pflanzenreich 4: $115,1901$.

Endlicheria panicularis (Nees)Mez, Jahrb. Bot. Gart. Mus. Berlin 5: 128, 1889 (pro syn.).

Aniba hirsuta (Nees)Pax ex Sampaio, Comm. Linh. Telegr. Matto-Grosso-Amazonas, Annexo 5, Bot. 10: 9, 1917. 


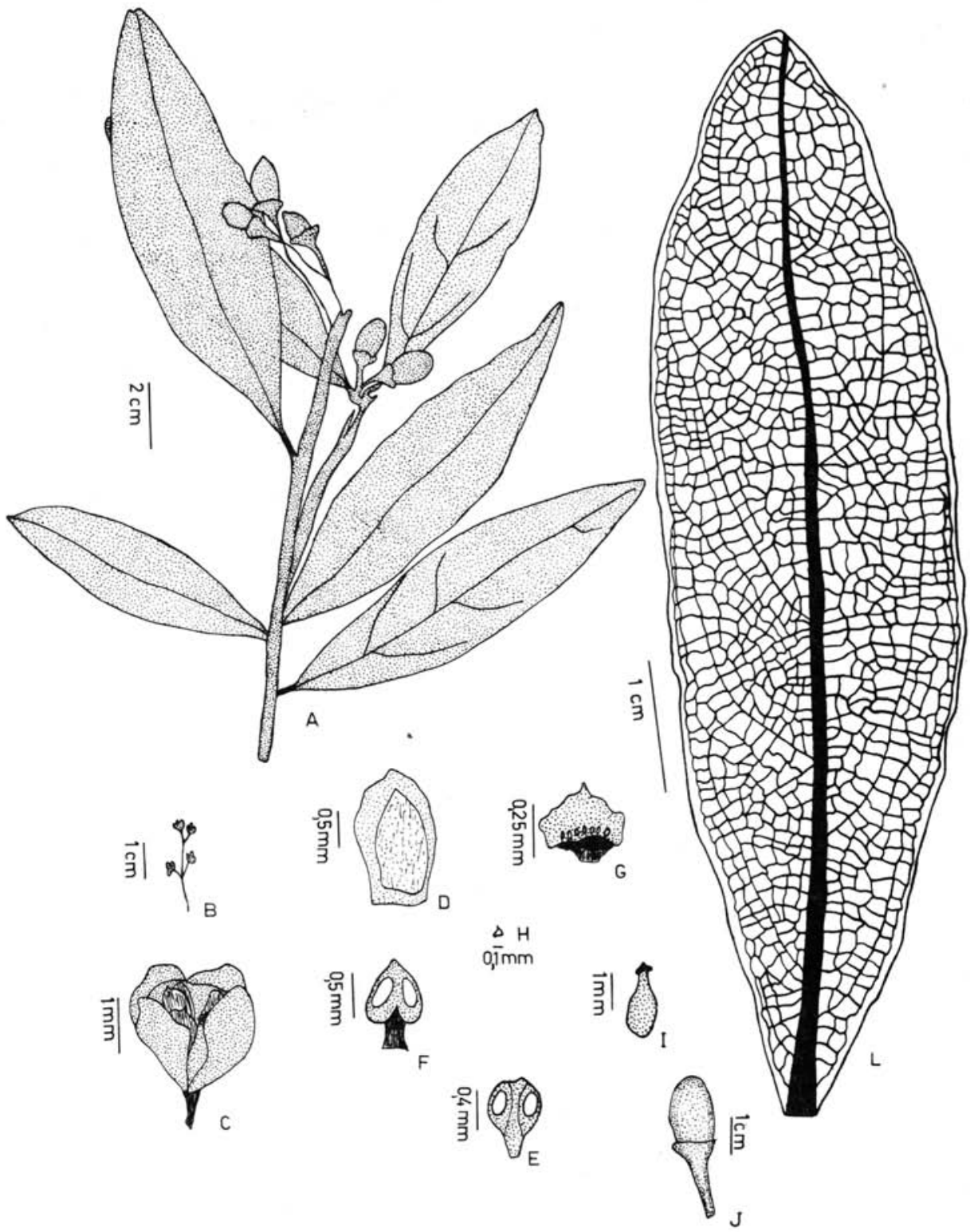

FIGURA 1 - Endlicheria peniculate: A - Ramo; B - parte da inflorescência; C - flor; D - tépala; E - estame da série I; F - estame das séries II e III; G - glândula; H - pistilo abortivo: I - pistilo, flor feminina: J - fruto; L - folha, venaçâo. (A, J, L, ICN 34943; B, C, D, E, F, G, H, ICN 46649; I, ICN 47808). 
Endlicheria longifolia (Nees)Mez, Jahrb. Bot. Gart. Mus. Berlin 5:119, 1889; Schimidt, Fedde. Repert. 31: 174,1933 .

Nomes vulgares: canela-burra, canela-cheirosa, canela-de-papagaio, canela-do-brejo, canela-dofrade, louro, canelã̃o.

Árvore ou arbusto com até $10 \mathrm{~m}$ de altura. Râmulos cilíndricos, tomentosos, raro glabrescentes, gemas tomentosas. Folhas alternas, cartáceas a rígido-coriáceas, estreitamente lanceoladas a largamente ovais; base aguda ou contraída para o pecíolo; ápice agudo ou obtuso. Folhas adultas com pêlos persistentes muitas vezes, na nervura mediana; brilhantes. Venação broquidódroma; as nervuras secundárias formam com a primária ângulos de $30^{\circ}$ a $60^{\circ}$. Inflorescências em panículas axilares; as jovens densamente cinéreo-seríceo-tomentosas, as adultas laxas, multifloras; râmulos patentes, tomentosos. Flores unissexuais, com $3-5 \mathrm{~mm}$ de diâmetro, glabras ou pilosas, verde-amareladas ou alvas ao vivo. Tépalas patentes, iguais. Flores masculinas com estames de anteras ovais, conectivo ultrapassando ligeiramente os lóculos. Estames internos com anteras obtusas; glândulas basais, globosas, sésseis. Ovário estéril, glabro. Flores femininas com estames estéreis, ovário ovóide, glabro, estilete engrossado; estigma peltado. Fruto baga elipsóide azulada (ao vivo) ou escura (material herborizado), cúpula avermelhada (ao vivo), pedicelo obcônico, delgado.

Distribuição geográfica: Brasil: Bahia, Espírito Santo, Minas Gerais, Mato Grosso, Rio de Janeiro, São Paulo, Paraná, Santa Catarina, Rio Grande do Sul, Piauí, Ceará; ocorre, ainda, no Peru, Equador e Paraguai.

Fenologia: floresce de setembro a fevereiro; frutifica de julho a dezembro.

Ocorrência: encosta inferior do nordeste, litoral, depressão central, encosta superior do nordeste, alto Uruguai, campos de cima da serra.

\section{Material examinado (Figura 2)}

BRASIL. Rio Grande do Sul: área do Pólo Petroquímico, Montenegro, 28/06/77, Ungaretti 396 (HAS 4660); Montenegro, 16/08/77, Ungaretti 529 (HAS 4886); Pólo Petroquímico, Montenegro, 07/06/77, Ungaretti 372 (HAS 4625); Morro Belizário, Torres, 23/05/75, Sidia 257 (HAS 1886); Torres, 25/09/77, Camargo s.n.; Osório, 06/10/76, Mattos \& Mattos 17248; Porto Alegre, 20/08/58. Mattos 1199; Dom Feliciano, 15/03/77, Mattos s.n.; Viamão, 05/10/75, Camargo 582; Guaíba, 26/08/78, Borges s.n. (PUC 1644); Butterberg, Montenegro, 22/05/50. Rambo s.n. (PACA 47145); Teresópolis, Porto Alegre, 03/10/46, Rambo s.n. (PACA 33858); Lagoa dos Quadros, Osório, 18/01/51, Rambo s.n. (PACA 49745); Cerro do Umbu, Osório, 31/12/34, Rambo s.n. (PACA 1418); São Leopoldo, 16/05/33, Rambo 145; Tannenwald, São Leopoldo, dez/42, Ram bo s.n. (PACA 10953); Vila Manresa, Porto Alegre, 1944, Rambo s.n. (PACA 26918); Morro da Polícia, Porto Alegre, out/44, Rambo s.n. (PACA 26997); Morro do Itacolomi, Gravataí, 11/01/50. Ram bo s.n. (PACA 45269); Nova Petrópolis, 13/06/49. Rambo s.n. (PACA 41965); São Leopoldo, 06/06/49, Ram bo s.n. (PACA 41869); Lagoa dos Quadros, Osório, 18/01/51, Rambo s.n. (PACA 49745); Vila Manresa, Porto Alegre, 03/10/46, Rambo s.n. (PACA 33856); Vila Manresa, Porto Alegre, 26/10/45, Rambo s.n. (PACA 29340); Parque Estadual de Torres, Torres, 11/07/72, Lindeman, Irgang et alii s.n. (ICN 28172); Parque Estadual, Torres, 03/07/72, Irgang, Girardi et alii s.n. (ICN 28180); Torres, 12/07/72, Lindeman, Irgang et alii s.n. (ICN 28175); Gruta da Glória, Porto Alegre, 26/10/68, Schultz \& Irgang s.n. (ICN 5886); Morro Itapeva, Torres, Lindeman, Irgang et alii s.n. (ICN 28171); Sítio Real, Morungava, Gravataí, 23/09/59, Baptista s.n. (ICN 2224); Torres, 11/04/77, Citadini s.n. (ICN 34475); Terra de Areia, Osório, $16 / 11 / 79$, Pedralli s.n. (ICN 46649); Lajeadinho, Torres, 15/11/79, Pedralli s.n. (ICN 46648); Parque Saint-Hilaire, Viamão, 17/12/73, Saafeld s.n. (ICN 22139); Porto Alegre, out/23, Scheiger 6106 (ICN 45457); Faxinal, Torres, 18/08/78, Waechter \& Baptista 906 (ICN 42515); Canela, 24/11/55, Menty s.n. (ICN 1264); Colônia São Pedro, Torres, 19/10/78, Waechter \& Weberling s.n. (ICN 42835); estrada para o Rio Turvo, Tenente Portela, 02/10/79, Pedralli s.n. (ICN 46376); Faxinal, Torres, 16/09/78, Citadini \& Franceschini 336 (ICN 42636); Parque Estadual, Torres, 10/07/72, Lindeman et alii s.n. (ICN 28229); Colônia São Pedro, Torres, 22/09/78, Pedralli s.n. (ICN 42643); Faxinal, Torres, $22 / 09 / 78$, Pedralli s.n. (ICN 42642); Banhado do Curtume, Torres, 03/12/76, Miotto 118 (ICN 33270); Itacolomi, Gravataí, 29/09/78, Fleig s.n. (ICN 42689); Santa Cruz do Pinhal, Taquara, fev/80, Brack s.n. (ICN 47044); Tenente Portela, 14/11/77, Irgang s.n. (ICN 35653); Morro Santana, Porto Alegre, 16/10/80, Brack s.n. (ICN 48309); Santa Cruz do Pinhal, Taquara, 12/10/80, Brack s.n. (ICN 48308); Colônia São Pedro, Torres, 22/09/79, Hagelund 12981; Parque Estadual Florestal do Turvo, Tenente Portela, 04/12/80, Brack s.n. (ICN 47808); Faxinal, Cambará do Sul, dez/80, Sobral 539 (ICN 48886); trevo para entrada de Venâncio Aires, 28/02/81, Pedralli s.n. (ICN 48946). 


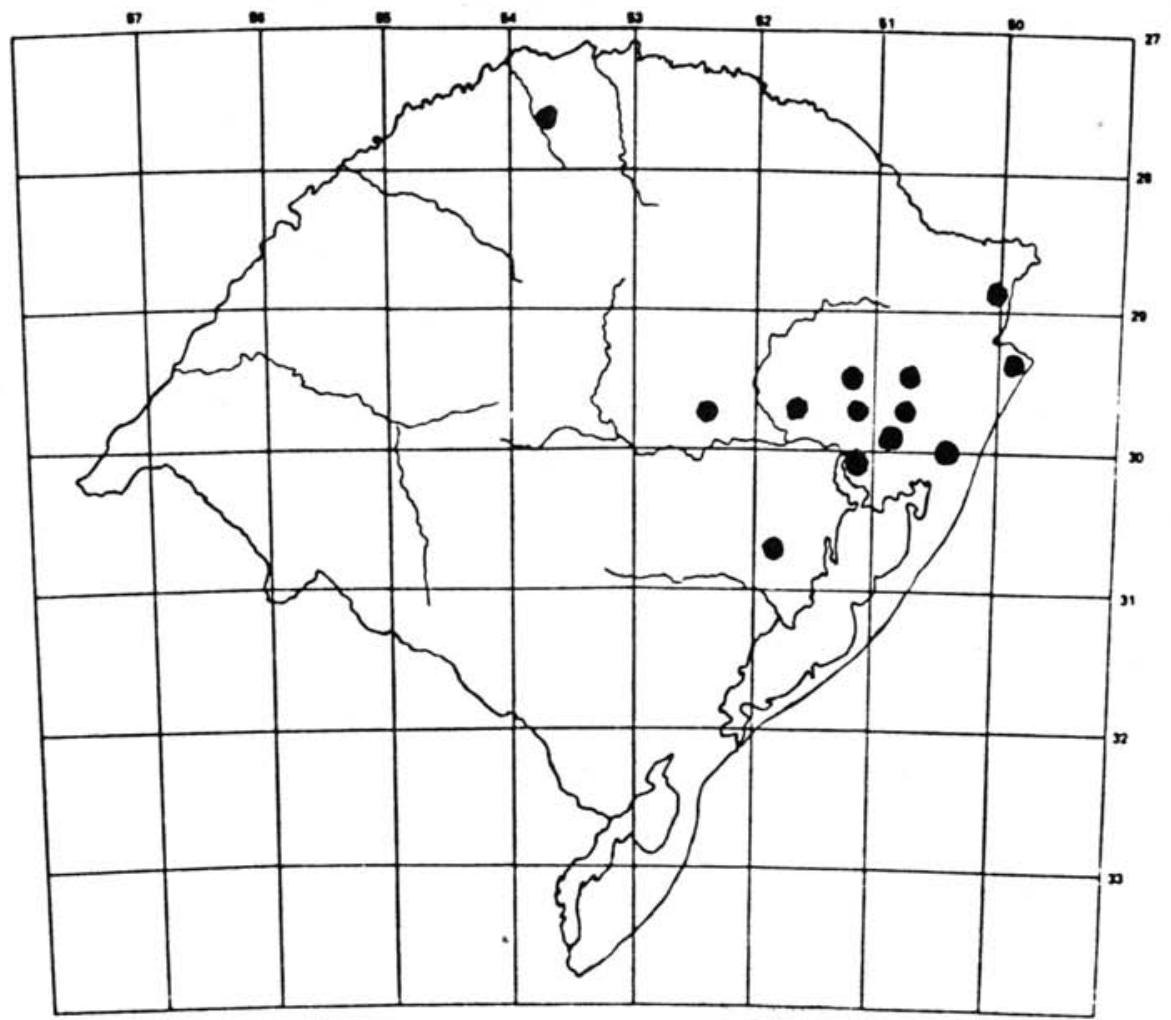

FIGURA 2 - Endlicheria paniculata: mapa de ocorrência

Santa Catarina: mata do Azambuja, Brusque, 14/08/49, Klein 07 (PACA 58297); Itajaí, 29/10/54, Klein 821 (PACA 65486); Sombrio, 05/02/46, Rambo s.n. (PACA 31584); Rio Tavares, Ilha de Santa Catarina, Florianópolis, 11/03/53, Reitz \& Klein 286 (PACA 58307); Ibirama, 25/04/55, Gavieski 149 (HBR 11320); Alto Rio D'una, Imaruí, 21/09/73, Bresolin 852 (HBR 41529); Blumenau, 14/10/54, Reitz \& Klein 2177 (HBR 41611); estrada D. Francisca, Joinvile, 23/08/57, Reitz \& Klein 4664 (HBR 41550); Serra do Matador, Rio do Sul, 01/08/58, Reitz \& Klein 6882 (HBR 36259); Pirão Frio, Sombrio, 04/09/59, Reitz \& Klein 9081 (HBR 9394); Jordão, Governador Celso Ramos, 28/03/72, Klein 10141 (HBR 41539); Morro das Aranhas, Florianópolis, 12/10/71, Bresolin 369 (HBR 41538); Costão Novo, Praia Grande, 29/01/80, Sobral s.n. (ICN 47160).

Paraná: Campinhinha, Piraquara, 29/01/50, Hatschbach 1850 (PACA 50929); Antonina, 23/03/66, Hatschbach s.n. (RB 175222).

São Paulo: Instituto de Biociências, Cidade Universitária, São Paulo, 19/08/72, Klein 10192 (HBR 37525).

Rio de Janeiro: Vista Chinesa, Rio de Janeiro, 10/11/77, Araújo 1932 (GUA 13723).

Espírito Santo: Santa Tereza, 25/02/65, Pereira 9837 (RB 128850).

Minas Gerais: Estação Experimental Coronel Pacheco, 18/10/55, Gomes 588 (RB 97634).

Laurus L., Sp. Pl., : 369, 1753 (ed. 1); Nees, Syst Laur. 579, 1836; Endlicher, Gen. Pl., 323, 1837; Meissner, Gen. Pl. 1: 327, 1841 et Gen. Pl. 1: 239, 1841; in DC., Prodr. 15(1): 233, 1864; Gay, Fl. 
Chil. 5: 294, 1849; Bentham in Bentham \& Hooker, Gen. Pl. 3: 163, 1880; Pax in Engler \& Prantl, Pflanzenfamilien 3(2)? 124, 1889; Kostermans, in Pulle, Fl. Surin. 2: 246, 1936.

Tipo: Laurus nobilis Lineu.

Ajovea Rafin., Sylva Tell., : 134, 1838.

Balanopsis Rafin., Sylva Tell., : 134, 1838.

Árvore ou arbustos, originários da região mediterrânea, cultivados em todo mundo. Folhas alternas, coriáceas, peninérveas. Flores unissexuais ou hermafroditas em umbelas axilares, pedunculadas e involucradas. Perianto tetrapartido, tépalas iguais. Flores masculinas usualmente com 12 estames em três ciclos, raras vezes com maior ou menor número; anteras introrsas, filetes com glândulas na metade da sua altura; ovário rudimentar. Flores femininas com quatro estaminódios grandes, alternos às tépalas, filetes com glândulas. Ovário ovóide, estilete curto, estigma discóide, triangular. Fruto baga, elipsóide, lisa, pedicelo do fruto subclaviforme no ápice.

Laurus nobilis L., Sp. Pl. 1: 369, 1753; Nees, Syst. Laur., : 579, 1836; Reichenbach, Ic. Fl. Germ. 12: 16, 1850 (táb. 673); Meissner, in DC., Prodr. 15(1): 233, 1864; Coste, Fl. France, : 3, 1906 (táb. 215 ); Kostermans, in Pulle, Fl. Surin. 2: 247, 1936. (Figura 3)

Nomes vulgares: louro, loureiro.

Arbusto ou árvore com até $10 \mathrm{~m}$ de altura, ramos e folhas glabros, verdes; gemas ovóides, cobertas com 4-6 escamas agudas, subseríceas. Folhas alternas, aromáticas, coriáceas, glabras, lanceoladas ou elíptico-lanceoladas, base aguda, margem freqüentemente ondulada, ápice agudo; face superior verde-escura, brilhante, nervura primária proeminente. Venação broquidódroma; as nervuras secundárias formam com a primária ângulos de $40^{\circ}$ a $55^{\circ}$. Flores em umbelas axilares, unissexuais, brevemente pecunduladas e involucradas; pedúnculos glabros, subcilíndricos. Pedicelos pubérulos, delgados, curtos. Flores verde-esbranquiçadas (ao vivo) ou amareladas; as quatro tépalas obovadas ou elípticas, obtusas, com nervuras longitudinais. Flores masculinas geralmente com 12 estames, às vezes 8 ou 10 ; anteras elípticas, introrsas, glabras; filetes delgados, glabros, com um par de glândulas grandes, subsésseis na metade da sua altura; os quatro estames exteriores (série I) habitualmente sem glândulas. Flores femininas com 2-4 estaminódios grandes, com ápice obtuso e glândulas grandes. Ovário elipsóide ou ovóide, glabro, estreitado até a base; estilete grosso, curto, estigma discóide, subtriangular. Fruto baga, escura, ovóide, pedicelo engrossado, às vezes ligeiramente claviforme até o ápice.

Distribuição geográfica: cultivada nas mais variadas regiões do mundo.

Fenologia: floresce de março a julho, setembro e dezembro; frutifica de janeiro a março, agosto e de outubro a dezembro.

Ocorrência: todas as regiões fisiográficas do Estado.

Material examinado (no qual estão baseados os pontos do mapa) (Figura 4)

BRASIL. Rio Grande do Sul: Rua Paraná nọ 30, Bento Gonçalves, 08/09/79, Pedralli s.n. (ICN 45724); Gramado dos Loureiros, Gramado, 07/12/74, Baptista, Irgang et alii s.n. (ICN 26850); Rua Tiradentes, Porto Alegre, 01/10/78, Pedralli s.n. (ICN 42660); São Francisco de Paula, 12/07/79, Pedralli s.n. (ICN 45137); Rio Grande, 06/10/78, Pedralli s.n. (ICN 42687); residência da Srta. Maria Pasquali, Bento Gonçalves, 12/04/80, Pedralli s.n. (ICN 47237); Vila Suzana, Canela, 16/04/79, Thomé s.n. (HAS 9370); Encruzilhada do Sul, 12/05/78, Mattos s.n. (HAS 18744); Badensertal, Montenegro, 08/09/49, Rambo s.n. (PACA 47827); Butterberg, Montenegro, 22/05/50, Rambo s.n. (PACA 47151) Nonoai, março/45, Rambo s.n. (PACA 28385); São Leopoldo, 25/03/35, Rambo s.n. (PACA 1865); Farroupilha, 21/05/56, Camargo 681 (PACA 59759); Chiapetta, 28/07/72, Borges s.n. (PUC 671): Viamão, 14/05/77, Livia A.M., Menino Deus, Porto Alegre, 15/08/76, Girardi s.n. (PUC 1522); Cascata, Pelotas, 28/07/65, Martins s.n. (PEL 7478); São Leopoldo, out/42, Rambo s.n. (PEL 7479); São Leopoldo, out/42, Rambo s.n. (HBR 433).. 

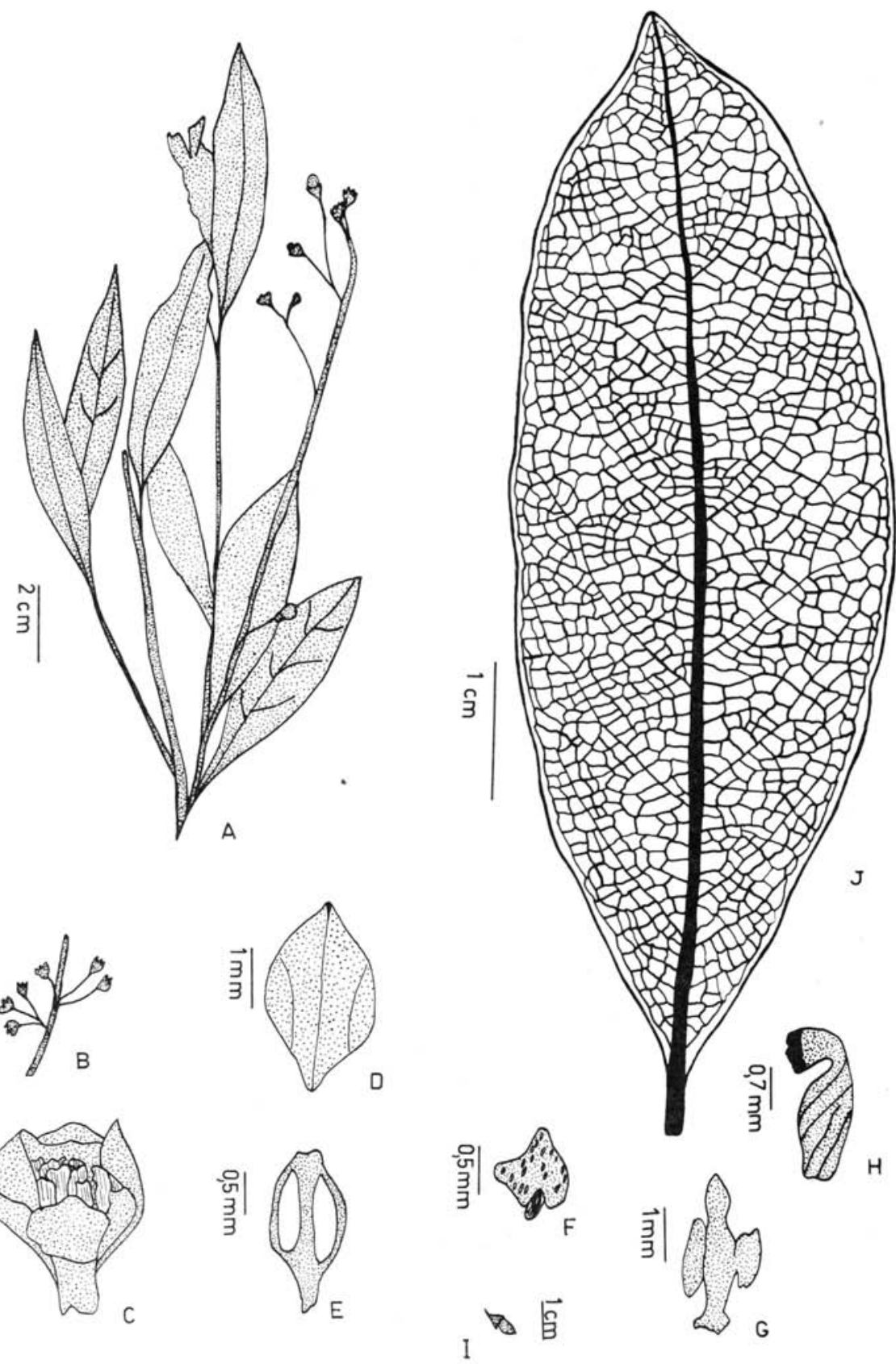
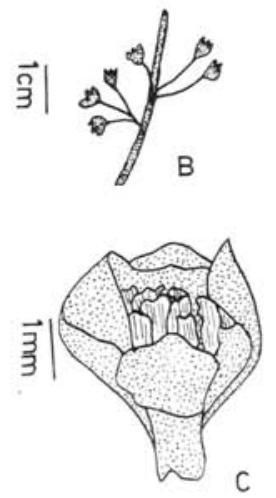
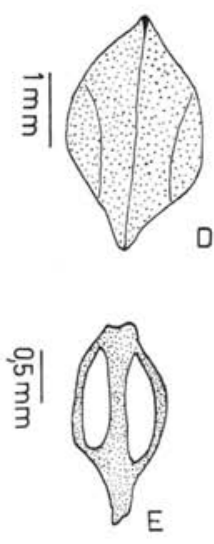

FIGURA 3 - Laurua nobilis: A - ramo: B - parte da inflorescência; C - flor: D - tépala: E - estame das séries I, II e III; F - glândula: G - estame com glândulas, flor feminina: H - estigma, flor feminina; I - fruto: J - folha, venação. (A, I, J, ICN 26850: B, C, D, E, F, ICN 45137: G, H, PUC 671). 


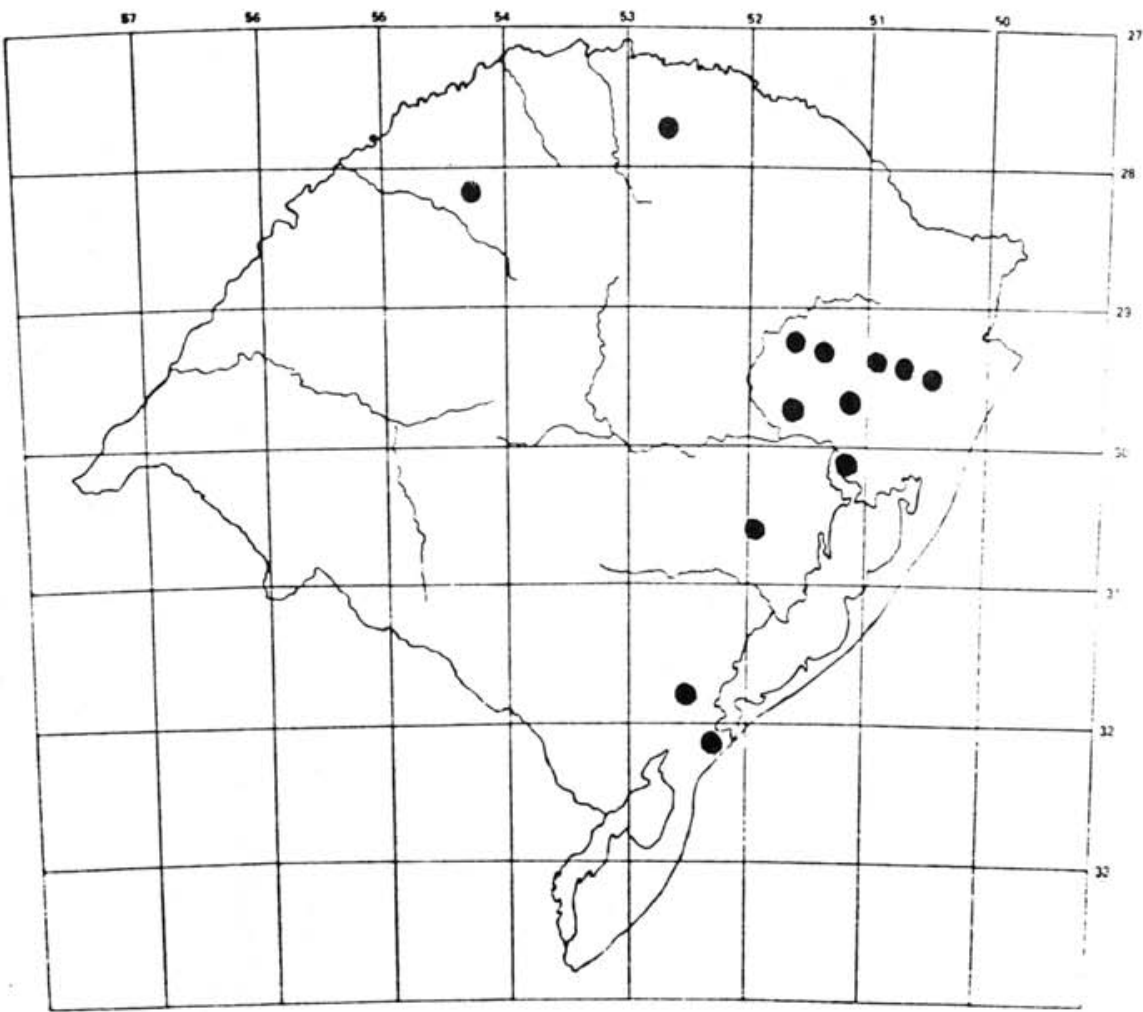

FIGURA 4 -Laurua nobilis: mapa de ocorrência.

Santa Catarina: Rio do Sul, 13/03/59, Reitz \& Klein 8563 (HBR 20396).

Paraná: Bom Retiro, Curitiba, dez/64, Saito 105 (RB 125824).

Rio de Janeiro: Campos, agosto/39, Sampaio 8469 (R 61245).

Itália - Ruínas do Forum Romano, Roma, 21/04/73, Matzenbacher s.n. (PUC 690).

Cryptocarya R. Br., Prodr. Fl. Nov. Holl. 1: 402, 1810; Meissner, in DC., Prodr. 15(1):68, 1864 et in Martius, Fl. Bras. 5(2): 114, 1866; Mez, Jahrb. Bot. Gart. Mus. Berlin 5: 7, 1889; Kostermans, in Humbert, FL Madagascar, : 81, 1950; in Journ. Sc. Res. Indonesia 1: 94, 1952 et in Bol. Tecn. Inst. Agron. Norte 28: 61, 1953 .

Tipo: Cryptocarya glaucescens $\mathrm{R}$. Br.

Cryptocarya Gay, F1. Chil. 5: 297, 1849.

Endocarpa Rafin., Sylva Tell., : 135, 1838.

Caryodaphne Blume ex Nees, Syst. Laur. : 225, 1836.

Salga da Blanco, Fl. Filipinas, : 221, 1845 (ed. 2).

Pseudocryptocarya Tescher, Engler, Bot. Jahrb. 58: 411, 1923.

Icosandra Phil., An. Univ. Chil. 91: 503, 1895.

Peumus Molina, Sag. Chile, : 185, 1782. 
Árvores ou arbustos, folhas alternas ou subopostas, cartáceas, glabras e pilosas. Inflorescências em panículas axilares, flores hermafroditas; tubo do perianto conspícuo, constrito abaixo dos lobos. Androceu de estames férteis em número de 9,6 ou 3, com os filetes mais curtos, em geral, que as anteras ovais ou subtriangulares; anteras dos estames dos verticilos externos introrsas, as do terceiro verticilo extrorsas, laterais ou introrsas; conectivo às vezes ultrapassando os lóculos. Terceiro verticilo de estames munido de glândulas junto à base dos filetes, às vezes pediceladas. Série IV do androceu composta de estaminódios cordado-ovados a cordado-sagitados, acuminados, foliáceos. Gineceu de ovário glabro, elipsóide, imerso no tubo do perianto; estigma pequeno, truncado, discóide. Fruto inteiramente incluído no tubo floral aumentado (àcrescente), deixando apenas um pequeno orifício no ápice. Endocarpo e exocarpo geralmente lenhosos e sulcados.

Gênero de ocorrência pantropical.

Chave para as espécies do gênero Cryptocarya $\mathrm{R}$. Br. do Rio Grande do Sul:

A. Panículas e flores glabras,

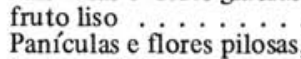

AA. Panículas e flores pilosas,
fruto costulado......

C. aschersoniana

...........

\section{C. moschata}

Cryptocarya aschersoniana Mez, Jahrb. Bot. Gart. Mus. Berlin 5: 11, 1889; Kostermans, Med. Bot. Univ. Utrecht 46:125, 1939; Vattimo, Rodriguésia 37: 227-9, 1966. (Figura 5).

Tipo: Cryptocarya aschersoniana Mez.

Cryptocarya moschata Nees, Linnaea 8: 37, p.p. (quoad cit. spc. Sellowi), 1833; Syst. Laur., : 213, p.p. (quoad cit. spec. Sellowi), 1836; Meissner, in DC., Prodr. 15(1): 74, 1864 (excl. cit. spec. Martii et Martini); in Fl. Bras. 5(2): 164, p.p. (excl. cit. spec. Martii et Martini); Mez, Jahrb. Bot. Gart. Mus. Berlin 5: 8, 1889 (cum forma angustifolia) et l.c.. : 9 (excl. cit. spec. Martii. Miersi 4375 et Pohli) Glaziou, Bull. Soc. Bot. France 59: 1921 et in Mém. 3:589, 1913; Kostermans, Med. Bot. Herb. Univ. Utrecht 42: 570, 1937 (quoad cit. spec. Sellowi s.n. et no 1375, Glaziou n? 18436 et 18437).

Nomes vulgares: canela-fogo, canela-pururuca, canela-de-porco, canela-cinza, canela-batalha.

Árvore com até $30 \mathrm{~m}$ de altura, râmulos glabros, cilíndricos, córtex aromático. Folhas alternas, rígido-coriáceas, glabras; na face dorsal subnítidas, na ventral opacas, elípticas, de base aguda, ápice acuminado, com a margem levemente ondulada, peninérveas, castanho-amareladas a avermelhadas em material herborizado. Pecíolos glabros, canaliculados, que continuam com a nervura primária. Venação broquidódroma; as nervuras secundárias formam com a primária ângulos de $45^{\circ}$ a $60^{\circ}$. Inflorescências em panículas axilares, ferrugíneas, iguais ou menores que as folhas, multifloras, tomentosas; râmulos grossos, geralmente curtos; brácteas pequenas. Flores hermafroditas, glabras, amareladas (ao vivo), ferrugíneas (em material seco); tépalas ovaladas; tubo do perianto cilíndrico; androceu um pouco mais curto que o perianto; filetes das séries I e II de estames curtamente adnatos aos lobos do perianto, pilosos na margem e na linha mediana. Anteras exteriores ovais, papiloso-hirsutas, no dorso subglabras. Glândulas grandes, subglobosas, curtamente estipitadas, pilosas. Anteras da série III ovais, com conectivo prolongado além dos lóculos, ápice obtuso, arredondado, truncado ou subtriangular. Estaminódios globososagitados. Gineceu de ovário glabro, ovóide a subgloboso, atenuado em estilete cilíndrico. Estigma subcapitado obtuso. Fruto drupáceo, globoso, liso, elipsóide, escuro, coroado pelos rudimentos do perianto, com pequeno colo na base.

Distribuição geográfica: Brasil, Estados do Rio de Janeiro, Minas Gerais, São Paulo, Paraná, Santa Catarina e Rio Grande do Sul.

Fenologia: floresce de outubro a abril; frutifica de dezembro a março.

Ocorrência: encosta superior do nordeste, campos de cima da serra, depressão central, litoral.

\section{Material examinado (Figura 6)}

Foto do tipo: neg. no 3842 (F, Chicago), Sellow s.n., Brasil (B). 

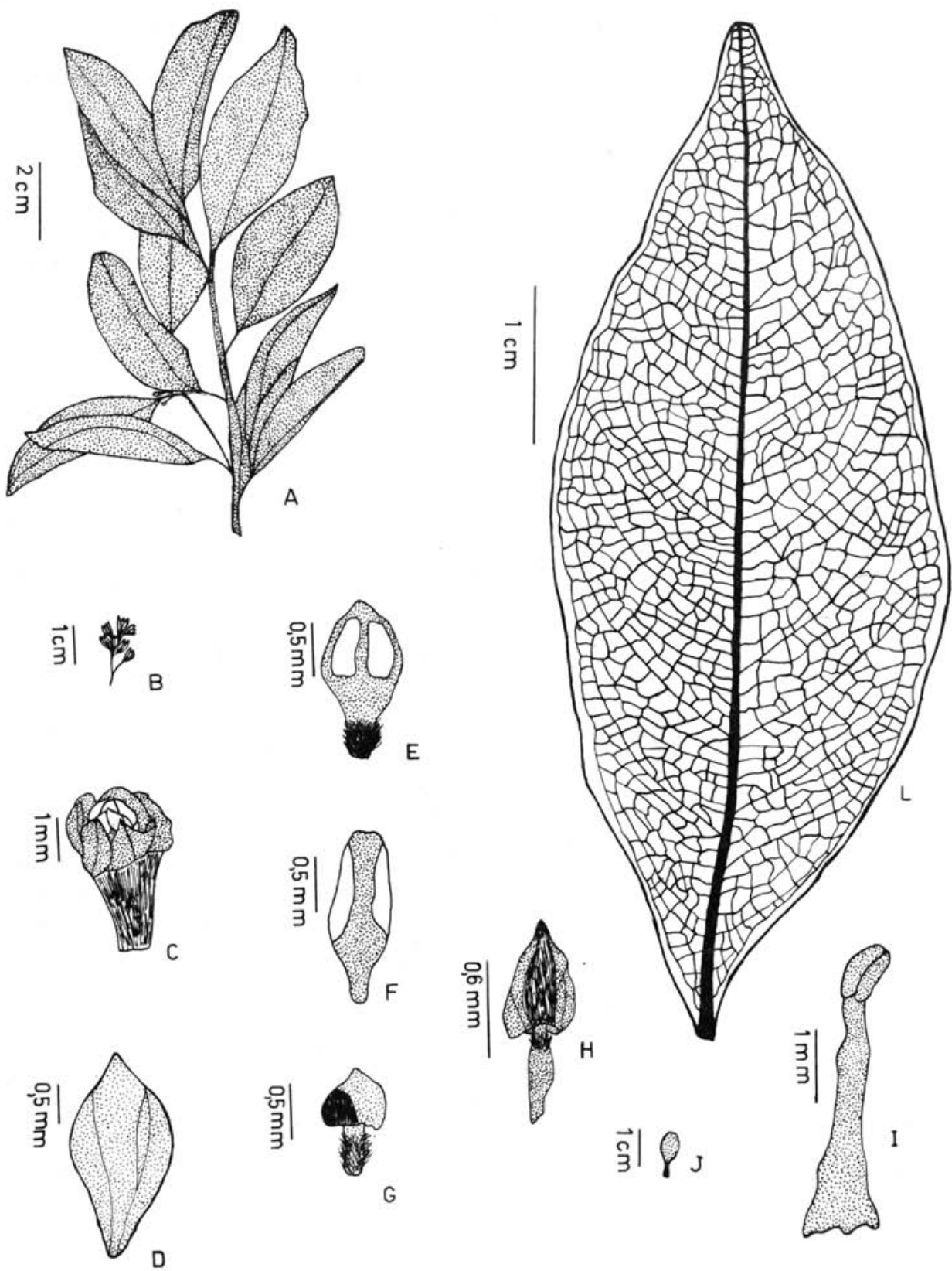

FIGURA 5 - Oryptocarya aschersoniana: A - ramo; B - parte da inflorescência: C - flor: D - tépala; $\mathrm{E}$ - estame da série 1: $\mathrm{F}$ - estame đas séries II e III: $\mathrm{G}$ - glândulas: $\mathrm{H}$ - estaminódio da série IV; I - pistilo: J - fruto jovem: L - folha, venação. (A, J, L, ICN 1260; B, C, D, E, F, G, H, I, ICN 43036). 
BRASIL. Rio Grande do Sul: Vila Oliva, Caxias do Sul, 19/08/78, Sobral s.n. (ICN 42628); Caracol, Canela, 27/12/72, Pelizzaro et alii s.n. (ICN 21724); São Francisco de Paula, agosto/57, Schultz s.n. (ICN 1587); Mato do Parque da Fenavinho, Bento Gonçalves, 28/10/78, Pedralli s.n. (ICN 43036); Estação Experimental de Fruticultura, Farroupilha, 25/03/57, Camargo 1311 (ICN 45257); Canela, 24/04/55, Menty s.n. (ICN 1260); Santa Rita, Farroupilha, 12/09/78, Martau s.n. (HAS 8733); Santa Rita, Farroupilha, 12/09/78, Soares et alii s.n. (HAS 8834); Santa Rita, Farroupilha, 12/09/78, Martau et alii s.n. (HAS 8715); Caracol, Canela, 27/07/72, Lindeman s.n. (ICN 28436); Sapucaia do Sul, 14/11/47, Schultz s.n. (ICN 602); São Francisco de Paula, 18/01/80, Sobral 236 (ICN 47093); Rio Pinto, Osório, 21/02/80, Sobral s.n. (ICN 47041); Morro Ferrabrás, Sapiranga, 16/07/80, Sobral 340 (ICN 47723); Morro Ferrabrás, Sapiranga, 16/07/80, Sobral 338 (ICN 47722); Estação Ecológica do Aracuri, Esmeralda, 21/09/80, Sobral s.n. (ICN 48199); Estação Ecológica do Aracuri, Esmeralda, 21/09/80, Pedralli s.n. (ICN 48210); Floresta Nacional do IBDF, São Francisco de Paula, 11/09/80, Pedralli s.n. (ICN 48221); Lageadinho, Torres, 26/09/80, Baptista et alii 5256; Fortaleza dos Aparados, Cambará do Sul, 29/01/81, Brack s.n. (ICN 48897); Gravataí, 07/01/81, Sobral 645 (ICN 48888); Fortaleza dos Aparados, Cambará do Sul, 29/01/81, Brack s.n. (ICN 48898); Parque dos Pinheiros, Farroupilha, 30/05/78, Aguiar et alii s.n. (HAS 5886).

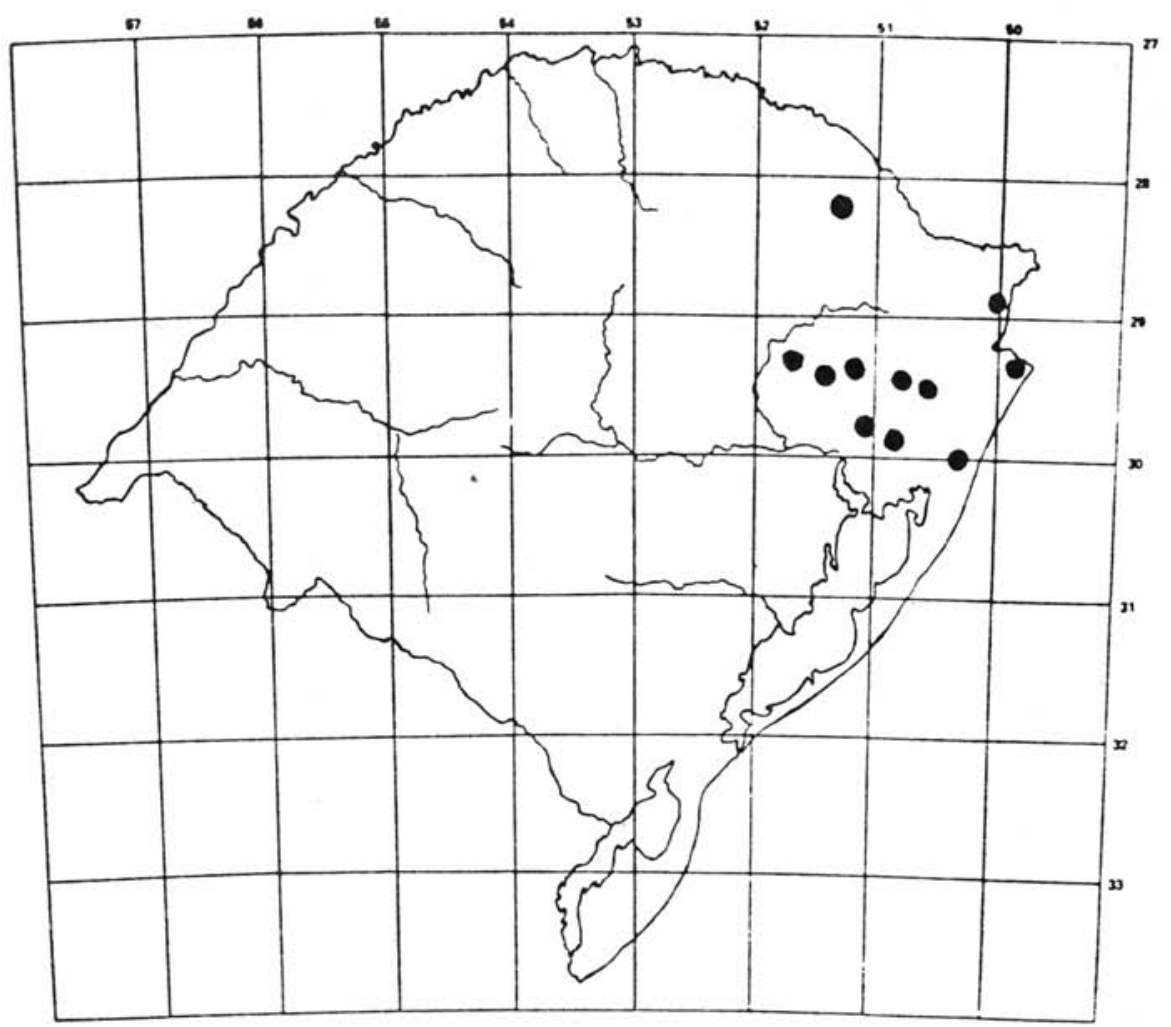

FIGURA 6 - Cryptocarya aschersoniana: mapa de ocorrência.

Santa Catarina: São Miguel do Oeste, maio/61, Schultz s.n. (ICN 2680); pinhal da Companhia Lauro Müller, Urussanga, 25/10/58, Reitz \& Klein 7523 (HBR 25530); Porto União, 09/12/62, Klein 3647 (PACA 66323); Ibirama, 05/02/56, Reitz \& Klein 2633 (PACA 66322); Serra do Matador, Rio do Sul, 26/01/59, Reitz \& Klein 8363 (PACA 66310); Lages, 04/12/62, Klein 3187 (PACA 66306); Morro Spitzkopf, Blumenau, 06/02/60, Reitz \& Klein 9533 (PACA 66298); Serra da Boa Vista, São José, 25/01/61, Reitz \& Klein 10745 (PEL 7000); Alto da Serra, Encruzilhada, Lages, 04/12/62, Klein 3184 (PEL 7395). 
Paraná: Loreto, nov/1915, Vecchi 204 (RB 6536).

Cryptocarya moschata Nees et Mart. ex Nees, Linnaea 8: 37, 1833 (excl. cit. spec. Sellowi); in Syst. Laur., : 213, 1836 (excl. spec. Sellowi); Meissner, in DC., Prodr. 15(1): 74, 1864; in Martius, Fl. Bras. 5(2): 164, 1866; Mez, Jahrb. Bot. Gart. Mus. Berlin 5: 8, 1889 (quoad cit. spec. Martii, Miersi 4275 et Pohli).: Kostermans, Med Bot. Mus. Herb. Univ. Utrecht 42: 571, 1939 (excl. cit. spec. Sellowi s.n. et 1375, Glaziou 18436 et 18437, quia ad Cryptocarya aschersoniana pertinent); in Bol. Técn. Inst. Agron. Norte 28:62, 1953; Vattimo, Rodriguésia 37: 229, 1966. (Figura 7).

Tipo: Cryptocarya moschata Martius.

Cryptocarya mandioccana Meissner, in DC., Prodr. 15(1): 75, 1864 et in Martius, Fl. Bras. 5(2): 165, 1866; Mez, Jahrb, Bot. Gart. Mus. Berlin, 5:10, 1889.

Nomes vulgares: noz-moscada-do-Brasil, canela cega, canela-branca, canela-batalha, canela-depapagaio, canela-fogo, canela-lageana.

Árvore com até $25 \mathrm{~m}$ de altura, râmulos amarelo-esverdeados, tomentosos, glabrescentes para a base, com pequenas estrias longitudinais, subcilíndricas no ápice. Gemas pequenas, densamente amarelo-tomentosas. Folhas com pecíolos canaliculados, coriáceas, elípticas ou lanceoladas, de base aguda e margem levemente ondulada, ápice acuminado ou obtusamente acuminado; folhas jovens pubérulas em ambas as faces, castanho-amareladas, avermelhadas a verde-acinzentadas; reticulação promínula, com pêlos na nervura mediana, peninérveas. Venação broquidódroma; as nervuras secundárias formam com a primária ângulos de $30^{\circ}$ a $60^{\circ}$. Inflorescências em panículas tirsóideas, axilares, multifloras, ferrugíneas, tomentosas, quase igualando as folhas em comprimento, bractéolas decíduas. Flores hermafroditas, alvas ou amareladas, parcamente pilosas; tubo do perianto estreitamente subcônico-urceolado, lobos mais longos que o tubo, iguais entre si, agudos. Androceu mais curto que os lobos do perianto; filetes das séries I e II de estames adnatos aos lobos do perianto na base, internamente tomentosos, mais curtos que as anteras; anteras das séries I e II subriangular-alongadas, de conectivo ultrapassando os lóculos, no ápice triangular a truncado; anteras da série III de deiscência lateral ou sublateral, ápice arredondado e obtuso, filetes pilosos; glândulas dispostas quase sem ordem entre os estames das séries exteriores e interior, grandes, subglobosas. Estaminódios da série IV grandes, sagitados, curtamente piloso-estipitados. Gineceu de ovário glabro, elipsóide, atenuado em estilete cilíndrico, estreitamente cônico para o ápice; estigma capitulado-discóide. Fruto drupa, amarelada ou alaranjada, envolta pelo tubo do perianto, elipsóide, com caneluras longitudinais (costulado).

Distribuição geográfica: Brasil, Alagoas, Rio de Janeiro, Minas Gerais, São Paulo, Paraná, Santa Catarina, Rio Grande do Sul, Pernambuco.

Fenologia: floresce de agosto a dezembro; frutifica de janeiro a abril.

Ocorrência: encosta inferior do nordeste, campos de cima da serra, depressão central, encosta superior do nordeste, litoral.

Material examinado (Figura 8)

BRASIL. Rio Grande do Sul: Parque dos Pinheiros, Farroupilha, 26/09/78, Soares et alii s.n. (HAS 8748); Serra, Nova Petrópolis, 03/01/40, Edésio s.n. (ICN 18392); Caracol, Canela, 04/01/73, Porto s.n. (ICN 28435); Canela, 24/04/76, Miotto 31 (ICN 33983); Mato da Fenavinho, Bento Gonçalves, 28/07/79, Pedralli s.n. (IĆN 45167); Kappesberg, Montenegro, 10/08/54, Rambo s.n. (PACA 32894); Vila Oliva, Caxias do Sul, 08/02/55, Rambo s.n. (PACA 56699); Vila Oliva, Caxias do Sul, 04/01/46, Ram bo s.n. (PACA 31030); Vila Oliva, Caxias do Sul, fev/48, Rambo s.n. (PACA 37179); Kappesberg, Montenegro, 09/11/45, Rambo s.n. (PACA 32814); Gramado, 26/12/49, Rambo s.n. (PACA 44998); Floresta Nacional do IBDF, São Francisco de Paula, 09/04/80, Pedralli s.n. (ICN 47187); Santa Rita, Farroupilha, 07/02/50, Rambo s.n. (PACA 45780); Farroupilha, 15/02/57, Camargo 1153 (PACA 59864); São Leopoldo, 1970, Rambo s.n. (PACA 6781); Santa Rita, Farroupilha, 28/01/49, Rambo s.n. (PACA 40290); Floresta Nacional do IBDF, São Francisco de Paula, 14/01/80, Pedralli s.n. (ICN 47061); Caracol, Canela, 02/01/73, Porto et alii s.n. (ICN 28434); Lodo Terápico, Gramado, 24/05/80, Pedralli s.n. (ICN 47327); Caracol, Canela, 27/12/72, Lindeman et alii s.n. (ICN 28436); Nove Colônias, Nova Petrópolis, 06/07/80, Sobral 336 (ICN 47653); Floresta Nacional do IBDF, São Francisco de Paula, 12/07/79, Pedralli s.n. (ICN 45131); Osório, nov/80, Sobral 481 (ICN 48877). 


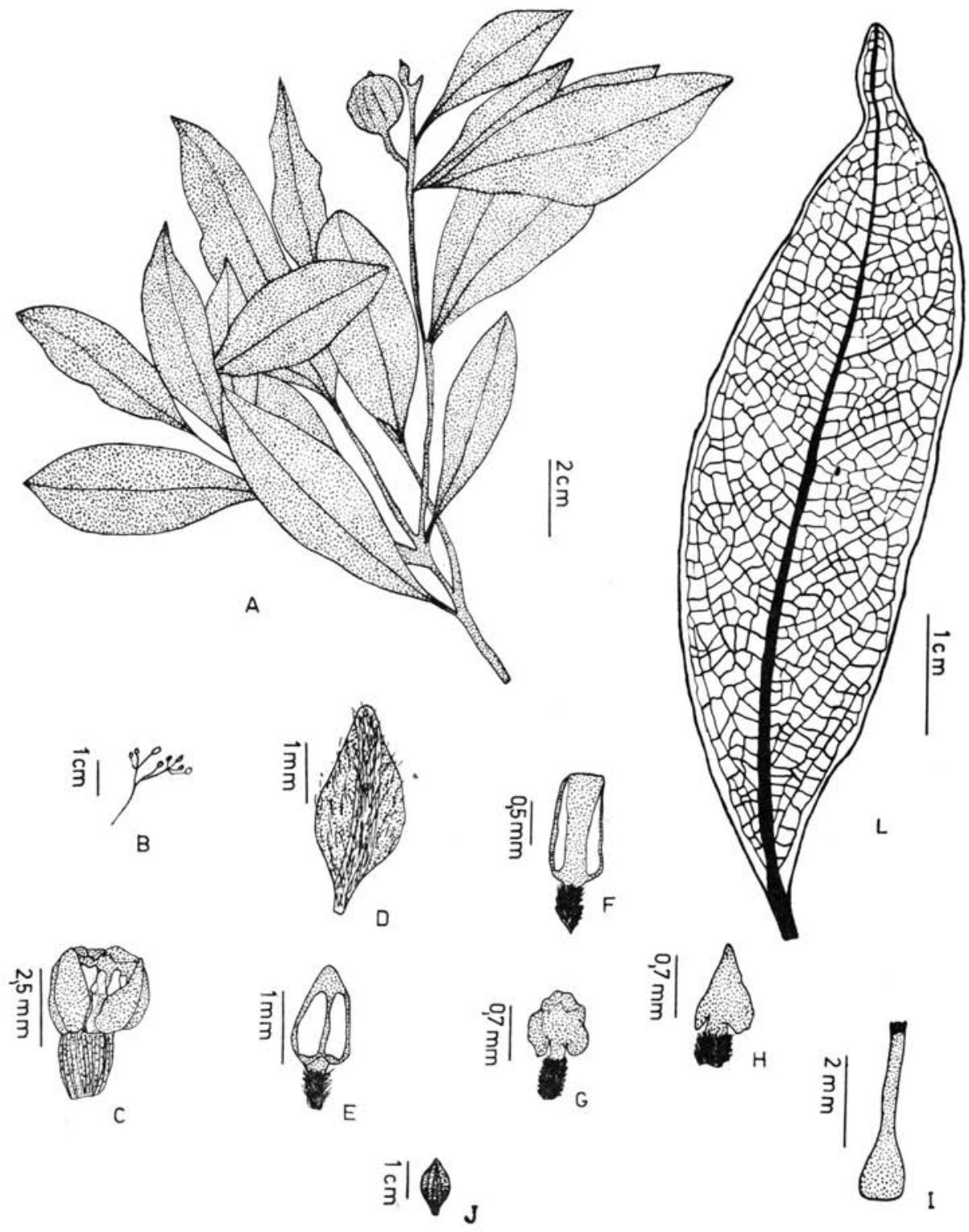

FIGURA 7 - Cryptocarya moschata: A - ramo; B - parte da inflorescência: C - flor: D - tépala: E - estame da série I; F - estame das séries II e III: G - glândula: H - estaminódio da série IV: I pistilo: J - fruto: L - folha, venação. (A, J, L, ICN 33983; B, C, D, E, F, ICN 45134; G, H, I, PACA $32814)$. 


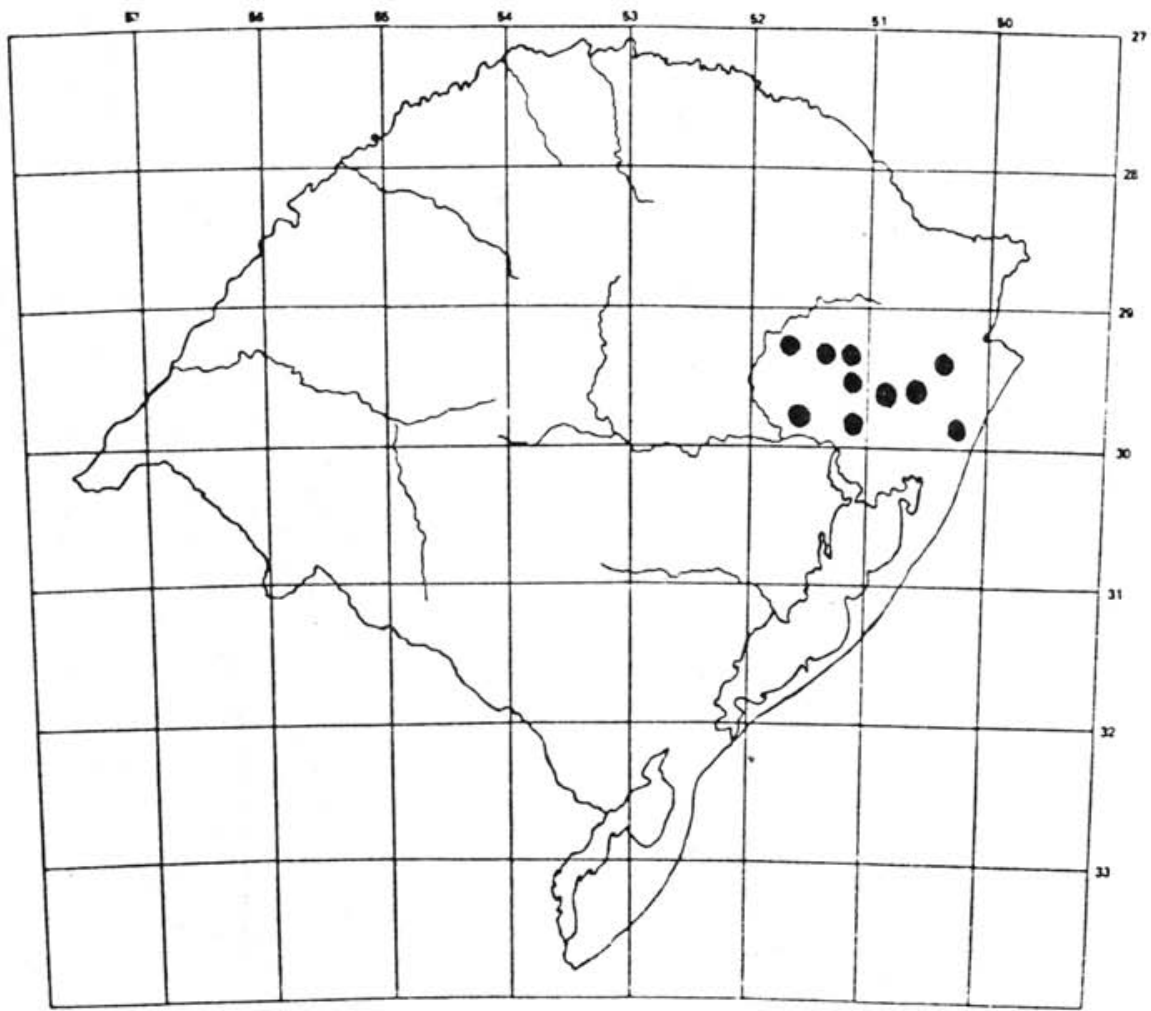

FIGURA 8 -Cryptocarya moschata: mapa de ocorrência.

Santa Catarina: Luís Alves, Itajaí, 10/01/56, Reitz \& Klein 2381 (HBR 9988); Itajaí, 30/09/54, Reitz \& Klein 2150 (HBR 10004); Morro da Fazenda, Itajaí, 10/03/54, Reitz \& Klein 1756 (HBR 9417); Sombrio, 09/02/46, Reitz \& Klein s.n. (PACA 31821); Braço Joaquim, Luís Alves, Itajaí, 04/11/54, Reitz \& Klein 2239 (HBR 9991); Pilöes, Palhoca, 18/01/56, Reitz \& Klein 2413 (HBR 9987); Horto Florestal, Ibirama, 04/02/56, Reitz \& Klein 2580 (HBR 9986).

São Paulo: Serra da Cantareira, 1918, Andrade 55 (R 31088); Mogi-Mirim, 06/10/31, Hoehne s.n. (RB 110591); Campinas, 22/09/78, Ferraz \& Mathes 892 (RB 184204).

Rio de Janeiro: Corcovado, 14/07/59, Duarte 4919 (RB 108038); Lagoa Rodrigo de Freitas, 07/02/61, Duarte 5492 (RB 180332).

\section{Referências Bibliográficas}

BARROSO, G.M. 1978. Sistemática de angiospermas do Brasil. Rio de Janeiro, Livros Técnicos e Científicos; São Paulo, EDUSP. V. 1.

BROWN, R. 1810. Prodromus florae Novae Hollandiae et insula Van Diemem. London, Weinheim. V. 1 .

FELIPE, G.M. \& ALENCASTRO, F.M.M.R. 1966. Contribuição ao estudo da nervação foliar das Compositae dos cerrados: Tribus Helenidae, Heliantheae, Inulae, Mutiseae e Senecioneae. An. Acad Bras Cien. 38: 125-57. 
GEMBALLA, G. 1955. Contribuição para a caracterização da essência de "Ocotea pretiosa Mez'. Rio de Janeiro, s. ed. 181 p., il.

GOTTLIEB, O.R. 1972. Chem osystematics on the Lauraceae. Phytochemistry II(5): 1537-1570.

HICKEY, L.J. 1973. Classification of the architecture of dicotyledonous leaves. Amer. J. Bot. 60: 1733.

KLEIN, R.M. 1974. Importância e fidelidade das Lauráceas na "Formação Araucária" do Estado de Santa Catarina. Insula, (7): 1-19.

KOSTERMANS, A.J.G.H. 1937. Revision of the Lauraceae, II. The genera Endlicheria, Cryptocarya (American species) and Licaria. Rec. Trav. Bot. Néerl., 34: 50-609. 1957. Lauraceae. Reinwardtia, 4(2): 193-256.

MEISSNER, C.F. 1866. Lauraceae. In: MARTIUS, C.F.P., Fl. Bras., Monachii, 5(2): 137-320.

MEZ, C. 1889. Lauraceae americanae. Jahrb. Bot. Gart. Mus. Berlin, 5: 1-556.

NEES VON ESENBECK, C.G. 1833. Revisio Laurinarum: A.B. Sellowio in Brasilia Collectarum et iam in Herbario Regio Berolinensis Asservatum. Linnaea, 8:36-51.

PAX, F. 1889. Lauraceae. In: ENGLER, A. \& PRANTL, K., Pflanzenf., Berlin, 3(2): 106-26.

RIZZINI, C.T. 1979. Plantas do Brasil: Árvores e madeiras úteis do Brasil; Manual de dendrologia brasileira. São Paulo, Edgar Blücher/EDUSP. 294 p.

SPRENGEL, K.P.J. 1825. Lauraceae. In: LINEU, C., Syst. Veg., 16 ed., Göttingen. 